\title{
Pemetaan Industri Pariwisata Di Kabupaten Tangerang Sebagai Tempat Promosi Potensi Investasi Melalui Aplikasi Gecom
}

\author{
Handy Januar Permana ${ }^{1}$ \\ Bugi Alfaridi ${ }^{2}$ \\ Haris Muhardi ${ }^{3}$ \\ ${ }^{1,2 \& 3}$ Program Studi Sistem Informasi, Fakultas Sains Dan Teknologi, Universitas Raharja \\ E-mail: handy.permana@raharja.info, ${ }^{2}$ bugi.alfaridi@raharja.info,$\underline{3 \text { haris.muhardi@raharja.info }}$
}

\begin{abstract}
Abstrak
Analitis sebuah pranata Negara, struktur data terlampau berharga.Observasi ini bermaksud mendapatkan struktur data geografis untuk penataan tujuan pariwisata, Struktur data Geografis sebagai salah satu prosedure ketika menyimulasikan satu kesulitan saat ini di bidang pariwisata Kabupaten Tangerang. Fungsi satu area di Kabupaten Tangerang patut dikembangkan diantaranya saat aspek pariwisata, permasalahan yang diarah Dinas Pemuda Olahraga Culture dan Turisme Kabupaten Tangerang ekslusif di sektor turisme yaitu tidak adanya berita destinasi pariwisata yang tersistem. Hal ini membutuhkan teknologi yang dapat menyajikan informasi destinasi pariwisata yaitu Pemetaan Destinasi Wisata seperti data yang menyampaikan penjelasan dalam laporan wisata harus mencakup data, gambar dan maps yang dapat diakses secara realtime dan fleksibel, sehingga para pelancong yang ingin berkunjung ke tempat objek pariwisata Kabupaten Tangerang namun tengah belum kenal letak atau letak tujuan wisata yang memikat untuk didatangi, dapat mengakses dan mengetahuinya melalui sebuah wadah yaitu aplikasi Geographic Computer. Dengan adanya Sistem ini, wisata di Kabupaten Tangerang akan menghadiahkan ketepatan waktu dan kelancaran saat mempublisitas tujuan wisata, pengunjung wisata tak berulang hadir ke Dinas Pemuda Olahraga Culture dan Turisme untuk meraih suatu berita yang akurat tentang destinasi rekreasi yang terletak di Kabupaten Tangerang. Maka dari itu, pengkajian ini mengusulkan sistem pemetaan pariwisata sebagai media promosi dan informasi sehingga objek wisata menjadi sebuah industri pariwisata yang berpotensi investasi dengan adanya dukungan teknologi informasi .Adapun struktur pemprograman pola dengan memanfaatkan UML dan mengaplikasikan pola analisa CSF (Critical Success Factor), karena pola pemprograman dan analisa ini benar-benar berguna dikerjakan sebelum mengembangkan laporan sistem pemetaan pariwisata.
\end{abstract}

Kata Kunci : CSF, Sistem Informasi Geografis, Pariwisata

\section{Abstract}

In a government institution, the information system is very important. This study aims to produce a geographic information system for mapping tourism destinations, Geographic Information Systems to be one method in solving a current problem in the tourism sector in Tangerang Regency. The benefits of a potential area in Tangerang Regency must be developed including in the field of tourism, the problems faced by the Tangerang Regency Youth, Sports, Culture and Tourism Office, especially in the Tourism Sector, namely the absence of systematized tourism destination information. This requires technology that can provide tourism destination information, namely Tourism Destination Mapping such as information that provides explanations in tourist information must include data, images and maps that can be 
accessed in real time and flexibly, so that tourists who want to visit the Tangerang Regency tourism object but still don't know the location or place of an interesting tourist attraction to visit, can access and find out through a container, namely the Geographic Computer application. With this system, tourism in Tangerang Regency will provide time and speed efficiency in promoting tourist destinations, tourist visitors no longer come to the Department of Youth, Sports, Culture and Tourism to get accurate information about tourist destinations in Tangerang Regency. Therefore, this study proposes a tourism mapping system as a media for promotion and information so that tourism objects become a tourism industry that has the potential for investment with the support of information technology. The system design method uses UML and applies the CSF (Critical Success Factor) analysis method, because this design and analysis method is very important to do before developing a tourism mapping system information.

Keywords : CSF, Geographical Information Systems, Tourism

\section{PENDAHULUAN}

Perkembangan ekonomi modern telah menunjukkan bahwa peranan sektor pariwisata memiliki peranan signifikan bagi pembangunan ekonomi di suatu wilayah, tidak terkecuali bagi Kabupaten Tangerang.Sektor pariwisata memiliki potensi yang besar untuk memajukan perekonomian Kabupaten Tangerang. Pemerintah Kabupaten Tangerang terus berupaya melakukan kajian untuk mengembangkan potensi sektor pariwisata demi kemajuan perekonomian masyarakat dan Pendapatan Daerah Kabupaten Tangerang, Pemerintah Kabupaten Tangerang selalu berupaya meluaskan dan mengelola manajemen tujuan wisata sehingga wisata yang ada di Kabupaten Tangerang mampu mengorbitkan kunjungan wisata serta memincut investor atau pengusaha untuk berinvestasi. Kepada Kompas.com, Kamis (21/11/2019), Bupati Tangerang Ahmed Zaki Iskandar mengungkapkan, ada tiga kategori wisata yang dimiliki Kabupaten Tangerang diantaranya wisata alam, wisata belanja dan wisata olahraga. Menurut Kepala Pariwisata pada Tahun 2021, Kabupaten Tangerang memiliki 7 kategori Pariwisata diantaranya yaitu, Wisata Alam, Wisata Buatan \& Edukasi, Wisata Sport \& Extreme, Wisata Kuliner, Wisata Belanja \& Kreatif, Wisata Religi dan Wisata Industri dan 116 tujuan wisata yang ada di Kabupaten Tangerang salah satunya, Telaga biru cigaru, Tebing Koja, Ekowisata Kemiri, Pantai Tanjung Pasir dan Tanjung Kait, Summarecon Digital Center, Ice BSD, World of Wonder, Scientia Square Park, Imperial Club Golf, BSD Extreme Park, Amsterdam Waterpark, Benteng Taruna Stadium Sport, The Breeze BSD, Taman makan PIK 2, Kedai Vakansi, Gerai Tangerang Gemilang, Supermal Karawaci, Summarecon Mall Serpong, AEON Mall, Makam Keramat Solear, PT. Surya Toto dan masih banyak lagi tujuan rekreasi yang ada di Kabupaten Tangerang. Saat ini Dinas Pemuda Olahraga Culture dan Turisme (DISPORABUDPAR) khususnya di bidang Pariwisata belum mempunyai media atau sistem informasi yang layak untuk bias mempublisitas program apa saja yang dapat diikuti bagi publik, eksklusif pada aspek Pariwisata dan memikat pengunjung asing atau domestik untuk lebih mengenal culture dan tujuan pariwisata yang berlokasi di area Kabupaten Tangerang.

\section{METODE PENELITIAN}

Desain riset ini mengarah demi mendapatkan informasi yang dibutuhkan saat rencana penggarapan penulisan skripsi ini, sehingga peneliti menmanfaatkan beberapa struktur yang dibuat sebagai berikut:

\section{Metode Pengumpulan Data}

Analitis menghimpun berita peneliti melakukan beberapa tahap antara lain :

A. Observasi 
Suatu pola untuk memeproleh laporan dengan terjun langsung pada tujuan yang diteliti terhadap informasi kepariwisataan dengan melihat langsung proses sistem yang berjalan saat ini pada Dinas Pemuda, Olahraga, Culture dan Turisme, maka melalui model ini penulis mampu mendapat data-data yang dibutuhkan dan mengetahui permasalahan serta menemukan solusi permasalahan pada Bidang Pariwisata.

B. Wawancara

Suatu metode untuk mendapatkan data terhadap pihak-pihak terkait seperti Dinas Pariwisata Kabupaten Tangerang agar peneliti dapat memahami permasalahan yang dihadapi dan penyelesaiannya dengan baik maka peneliti akan melakukan interview langsung dengan Kepala Seksi Pariwisata Ibu Nani Mulyani. S. Sn dengan mengerjakan pendataan terhadap hasil tanya jawab demi dijadikan asal muasal laporan.

C. Studi Pustaka

Selain menjalankan pemantauan dan tanya jawab, penulis juga menggali informasi dengan cara studi pustaka. Tatkala proses ini penulis berikhtiar untuk menekuni artikulasi yang berhubungan bersama tittle yang direkam. Sehingga periset memperoleh bayangan menurut teoritis yang berarti demi mendukung penganalisaan dan pemprograman maupun riset ini.

\section{Metode Analisa}

Ketika riset ini periset memakai pola analisa CSF (Critical Success Factor) selaku cara untuk menjabarkan secara faktual sebagai kian jelas untuk memastikan kegiatan yang wajib dilaksanakan dan berita segala yang diperlukan.

\section{Metode Perancangan Sistem}

Atas pola pemprograman ini, periset memakai desain Unified Modeling Language (UML), dimana diagram UML yang dipakai adalah Use case Diagram, Activity Diagram, Sequence Diagram dan Class Diagram selaku sketsa sebuah draf pola yang dianjurkan. Bahasa pemrograman yang dipakai ialah Dart, Framework Flutter adalah Software Development Kit untuk pembuatan aplikasi mobile, Visual Studio Code untuk membuat Project dan database untuk record datanya adalah MySQL.

\section{Kaidah Riset}

Pada desain pengetesan ini penulis mengaplikasi sistem Black Box Testing untuk melihat apakah desain sudah mencukupi keperluan pemakai yang diinterpretasi tatkala permulaan minus mengekspos listing program.

\section{Literature Review}

Selanjutkan merupakan riset yang sudah dikerjakan dan mempunyai hubungan yang sesuai pada riset yang akan diperiksa dalam riset skripsi ini. Seraya usaha melengkapi riset bahwa butuh dilakukan analisis teks , diantaranya yaitu:

1. Riset ini diteliti oleh Postinus Gulo, Andy Paul Harianja, tahun 2017 yang berjudul "Perancangan Media Informasi Pengenalan Kebudayaan Dan Pariwisata Nias Selatan Berbasis Web". Riset ini bertujuan demi mengenalkan budaya dan turisme di Nias selatan selaku menyeluruh, baik dalam arah kunjungan, hotel, tempat rekreasi, tempat makan, oleh-oleh dan pelancong dapat mengusulkan pendapat dan keluh kesah langsung kepada Admin. Untuk jasa turisme cara ini ialah kemudahan untuk 
mengaplikasikan program kerja yang sudah dipersiapkan untuk mempublisitaskan budaya dan turisme di wilayah Nias selatan secara lebih luas.

2. Penelitian yang dilakukan oleh Darman Umagapi, Arisandy Ambarita, tahun 2018 yang berjudul "Bentuk fakta Geografis rekreasi Bahari pada Dinas Rekreasi Kota Ternate". Riset ini bertujuan untuk merancang skema laporan geografis tujuan rekreasi bahari pada Dinas Turisme Kota Ternate. Penerapan Skema Laporan Geografis rekreasi bersama memberdayakan teknologi berita ini, meringankan Dinas Rekreasi Kota Ternate mensuguhkan laporan untuk pelancong, sekiranya para pelancong dapat mengetahui laporan tujuan rekreasi bahari kapanpun.

3. Menurut Abas Sunarya dan Lisa Anisah dalam Jurnal CERITA Vol. 4 No. 1 (2018:78), literature review atau riset sebelumnya merupakan format literatur tentang sebuah invensi yang telah ditemukan oleh akar sebelumnya (empirical finding) dan berkaitan dengan riset.

4. Riset yang dikerjakan oleh Helmi Kurniawan, Muhammad Rusdi Tanjung, tahun 2017 yang berjudul "Sistem Informasi Geografis Tujuan Rekreasi Nature di Provinsi Sumatera Utara Berbasis Mobile Android", Sistem informasi yang menyediakan berita tempat-tempat rekreasi Sumatera Utara sudah ramai dibangun. Akan tetapi sekedar menayangkan visual maupun gelarnya saja yang disediakan termasuk corak denah, perangkat reklame koran maupun web yang tidak menyediakan arahan langsung ke area rekreasi yang dituju. Problematika yang diperoleh dari berita media tersebut bagi pelancong ialah tidak mendapatkan arahan langsung area rekreasi letak posisi secara geografisnya. Hal ini dibutuhkan teknologi yang dapat menyajikan informasi tujuan tur yaitu Sistem informasi geografis (SIG) Sebagaimana kondisi dengan berita yang menginformasikan penjelasan dalam informasi wisata harus meliputi berita dan visual asli. Sebagaimana para pelancong yang berminat berkunjung ke Provinsi Sumatera Utara namun tengah belum tahu area tujuan rekreasi yang interest untuk didatangi dapat mengaksesnya. Untuk menghandle problem tersebut pemakalah mengaplikasi pendekatan pada model pemetaan digital berupa SIG dengan berbasis mobile android menggunakan google maps sebagai peta digital. Struktur berita geografis ini berarah demi menghibahkan keringanan dan kecekatan kepada masyarakat dalam mendapatkan berita perihal Tujuan Tur Alam di Provinsi Sumatera Utara.

\section{HASIL DAN PEMBAHASAN}

\section{Rancangan Diagram}

\section{a. Use Case Diagram}




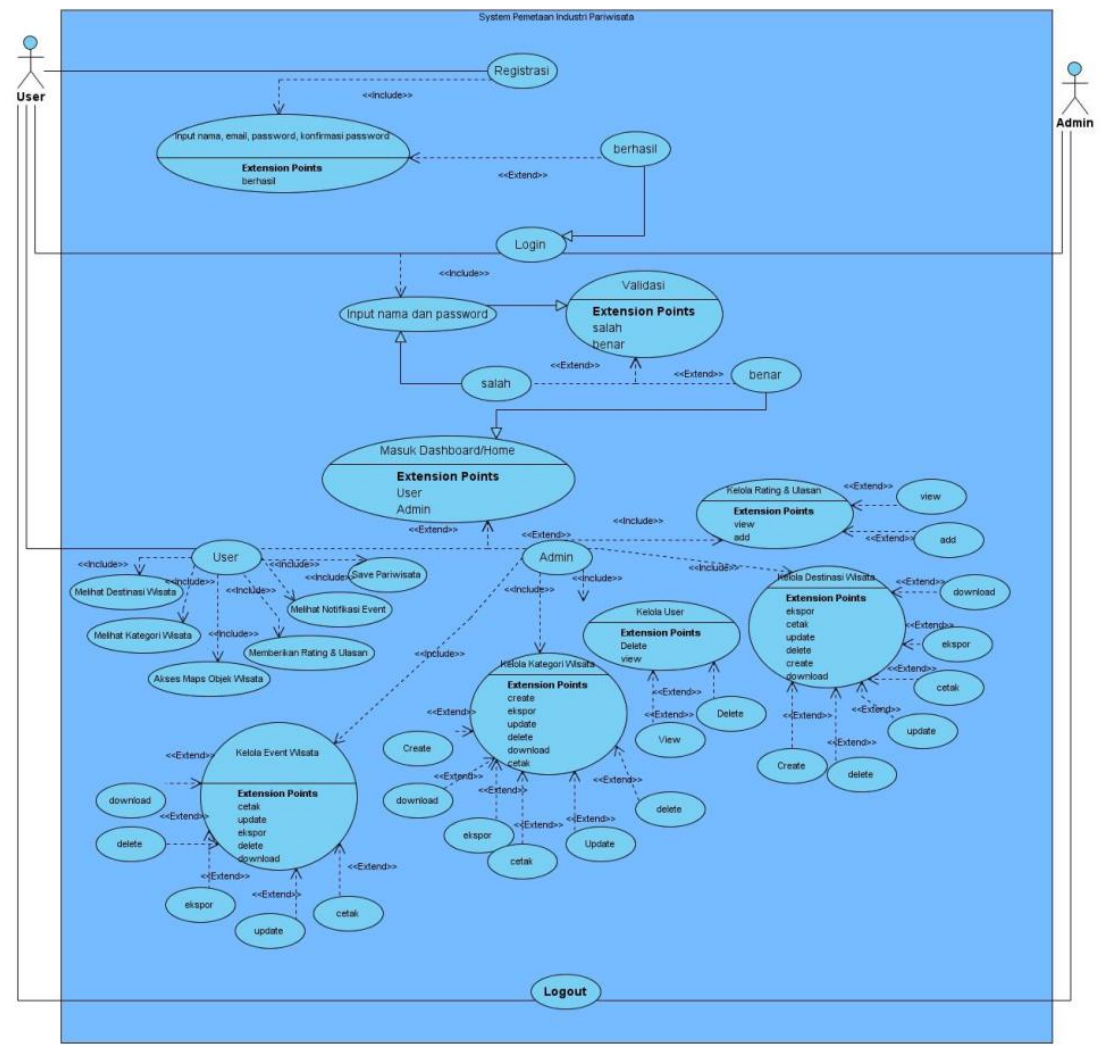

Visual 1 Use Case Diagram yang Diusulkan

Bersumber pada Use Case Diagram Sistem Pemetaan Industri Pariwisata yang dianjurkan terdiri atas :

1. 1 (Satu) Pola yang menyeluruhi semua aktivitas pola Pemetetaan Industri Pariwisata

2. 2 (Dua) Actor yang melancarkan aktivitas, diantaranya : User dan Admin

3. 44 (Empat Puluh Empat) Use Case dalam satu sistem

\section{b. ActivityDiagram}




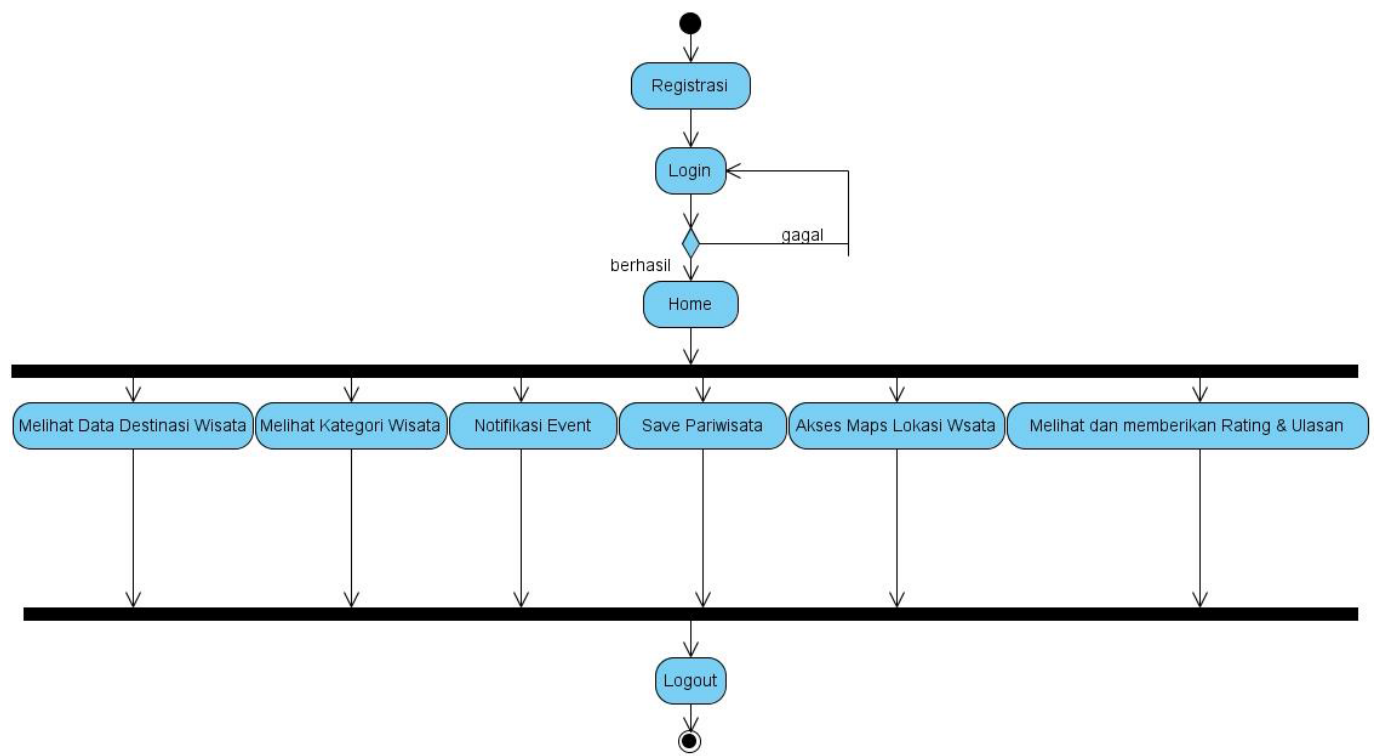

Visual 2 Activity Diagram User yang Diusulkan

Bersandarkan Activity Diagram User Pola Pemetaan Industri Pariwisata yang disarankan terdiri atas :

1. 1 (Satu) Initial node yang diawali

2. 10 (Sepuluh) Action state sebagai plot prosedure pada program pola usulan

3. 1 (satu) final state yang berguna selaku ciri final dari plot prosedure program pola ajuan. 


\section{c. Sequence Diagram}

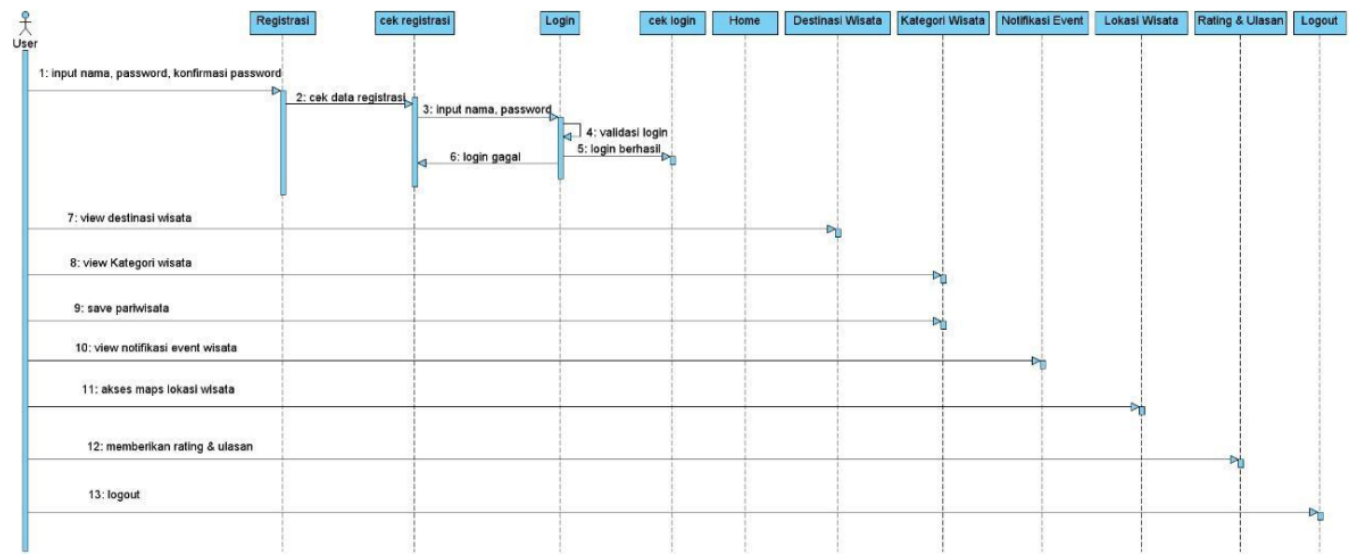

Visual 3 Sequence Diagram User yang Dianjurkan

Bersandarkan Sequence Diagram User Sistem Pemetaan Industri Pariwisata yang diajukan terdiri atas :

1. 2 (Dua) Aktor yang menjalankan dereta prosedure pada pola gagasan.

2. 11 (Sebelas) sasaran yang saling berkaitan yaitu : Registrasi, Cek registrasi, Login, cek login, Home, Destinasi Wisata, Kategori Wisata, Notifikasi Event, Lokasi Wisata, Rating Ulasan, dan Logout

3. 13 (Tiga Belas) pesan dari hubungan sesama sasaran yang berisi atas berita acara yang tengah berlangsung.

\section{Rancangan Program}

a. Bentuk Menu Home

1. Bentuk Menu Home Aplikasi

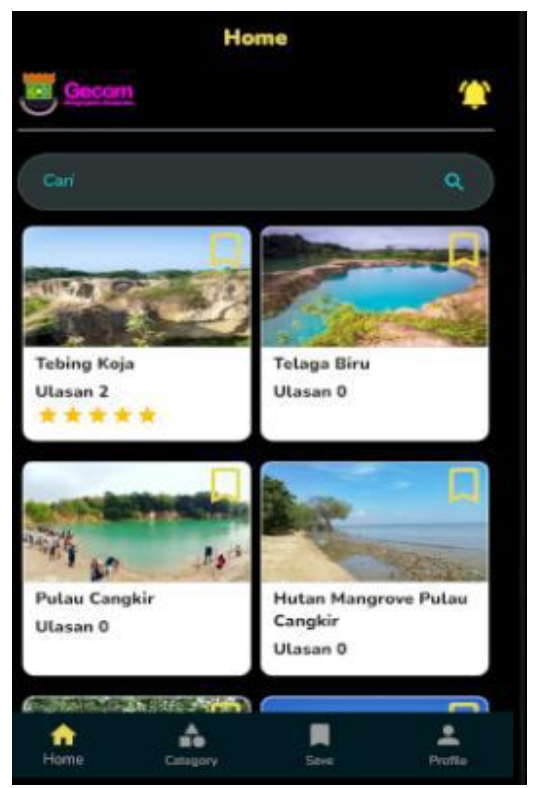

Gambar 4 Tampilan Menu Home Mobile

b. Bentuk Menu Category 
1. Bntuk Menu Category Aplikasi Mobile

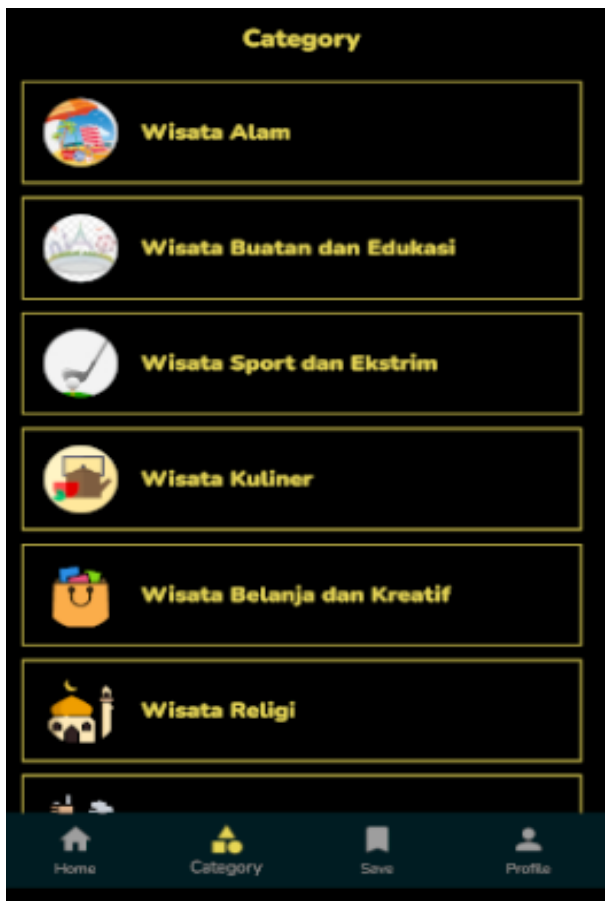

Gambar 5 Bentuk Menu Category Mobile

c.

Bentuk Menu Save Wisata

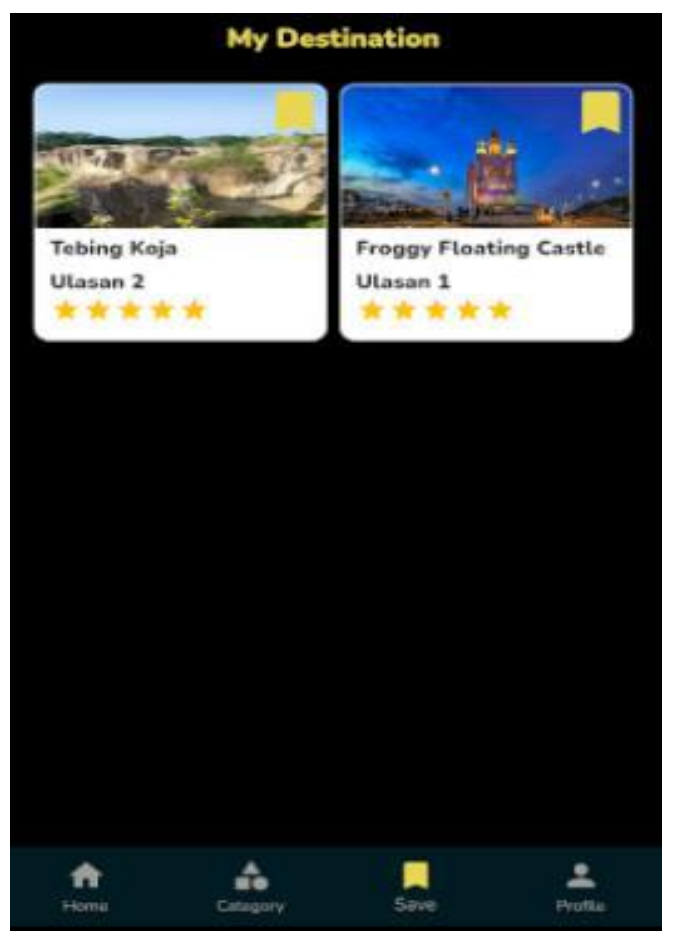

Gambar 6 Bentuk Menu Save Wisata

\section{d. Bentuk Menu Profile}




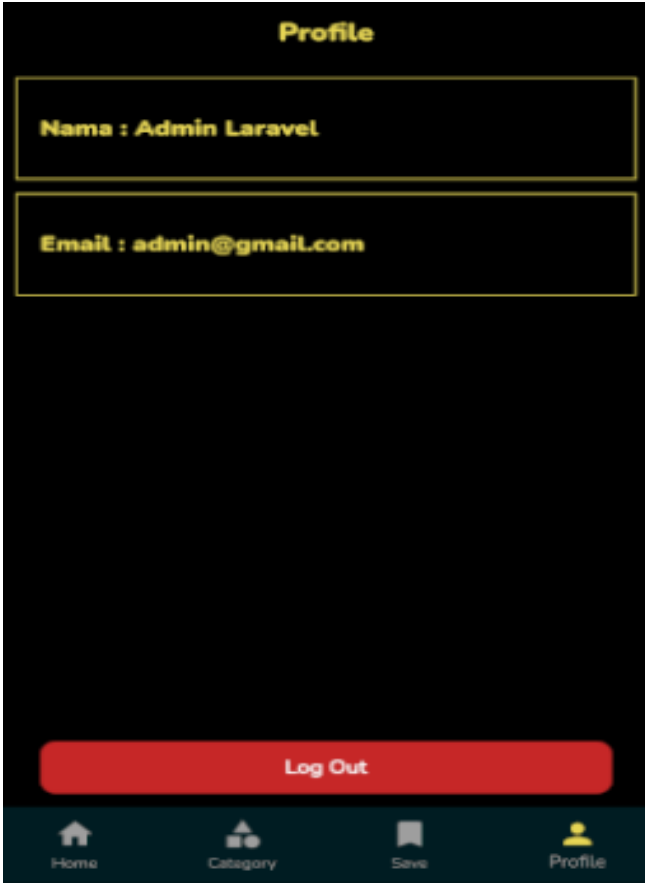

Gambar 7 Bentuk menu profile

e. Tampilan Notifikasi Event

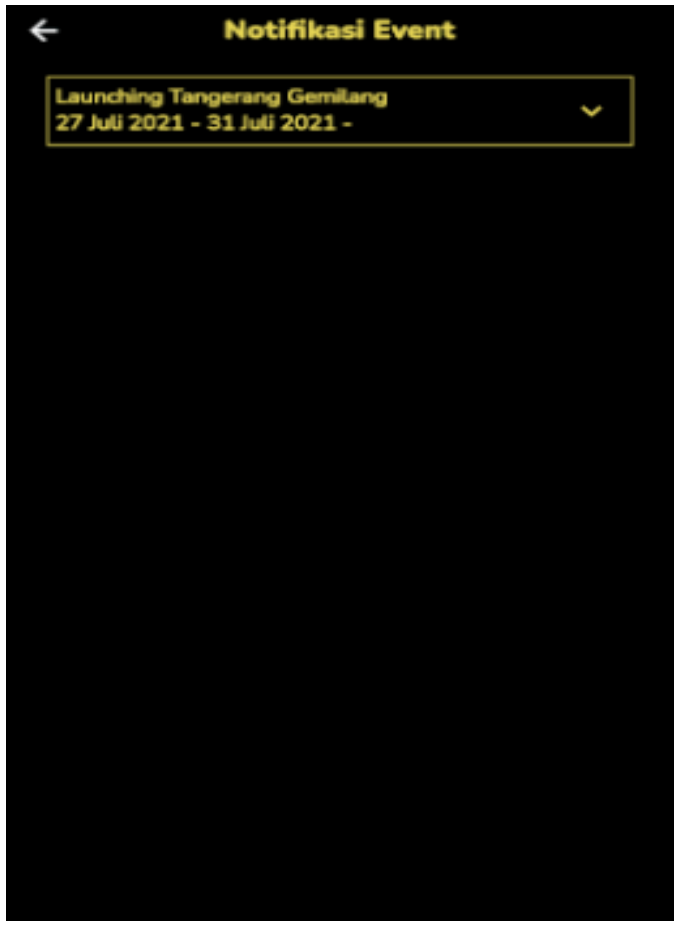

Gambar 8 Tampilan Notifikasi Event 
F. Tampilan Menu Informasi Destinasi Wisata

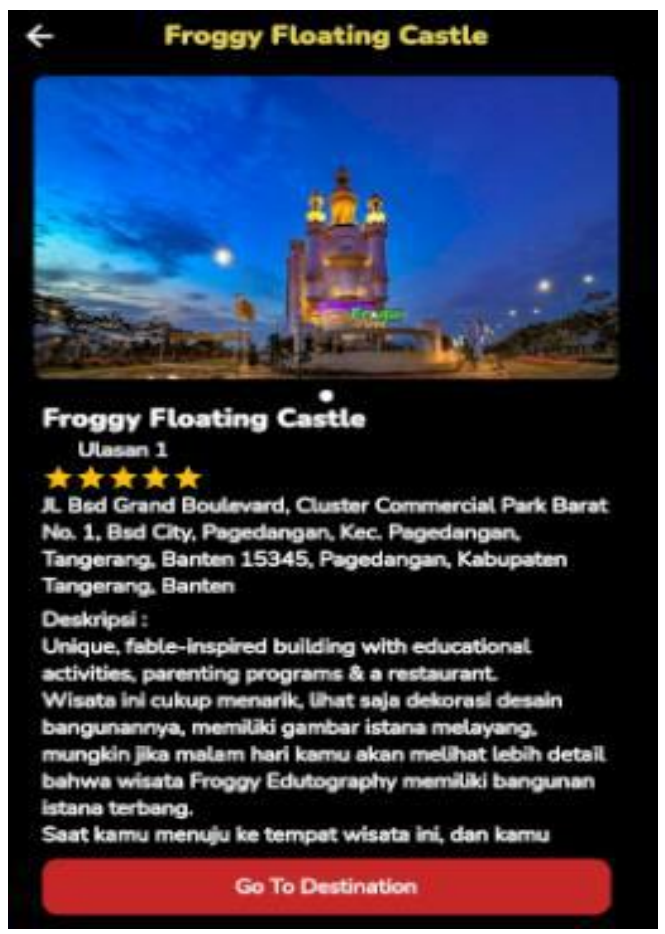

Gambar 9 Tampilan Menu Informasi Destinasi Wisata

Black Box Testing

\begin{tabular}{|c|c|c|c|c|c|}
\hline No & Nama Pengujian & Test Case & $\begin{array}{l}\text { Hasil yang } \\
\text { diharapkan }\end{array}$ & $\begin{array}{l}\text { Hasil } \\
\text { Pengujian }\end{array}$ & $\begin{array}{l}\text { Kesimpula } \\
\text { n }\end{array}$ \\
\hline $\mathbf{1}$ & $\begin{array}{l}\text { Login dengan } \\
\text { username dan } \\
\text { password yang } \\
\text { benar }\end{array}$ & 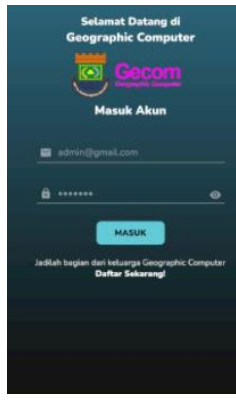 & $\begin{array}{l}\text { Berhasil } \\
\text { masuk ke } \\
\text { menu Home }\end{array}$ & 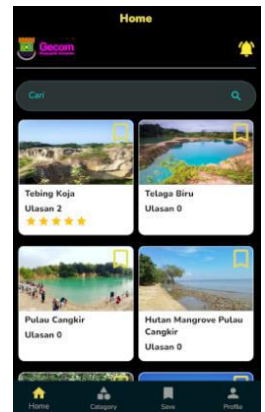 & Valid \\
\hline
\end{tabular}


ISSN: 2461-1409

Journal Sensi

Online ISSN: 2655-5298

\begin{tabular}{|c|c|c|c|c|c|}
\hline 2 & $\begin{array}{l}\text { Login dengan } \\
\text { username dan } \\
\text { password yang } \\
\text { salah }\end{array}$ & - & $\begin{array}{l}\text { Sistem akan } \\
\text { menolak akses } \\
\text { login }\end{array}$ & 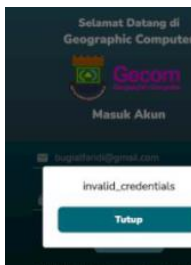 & Valid \\
\hline 3 & $\begin{array}{l}\text { Mengosongkan } \\
\text { Username dan } \\
\text { Password }\end{array}$ & 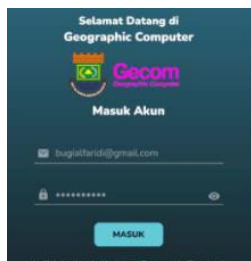 & $\begin{array}{l}\text { Tolong } \\
\text { lengkapi form } \\
\text { input }\end{array}$ & 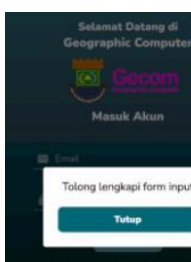 & Valid \\
\hline 4 & $\begin{array}{l}\text { input data } \\
\text { destinasi wisata }\end{array}$ & 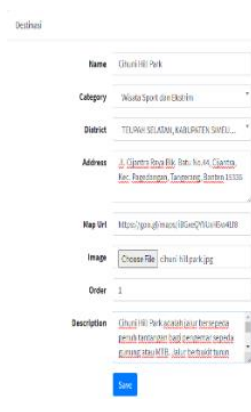 & $\begin{array}{l}\text { Berhasil input } \\
\text { data destinasi } \\
\text { wisata }\end{array}$ & 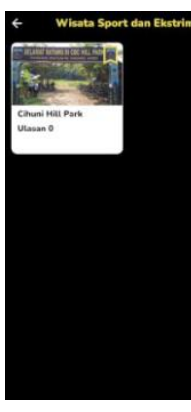 & Valid \\
\hline 5 & $\begin{array}{l}\text { Klik Print } \\
\text { destinasi wisata }\end{array}$ & 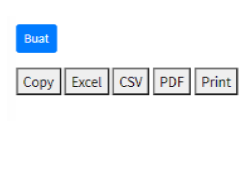 & $\begin{array}{l}\text { Berhasil } \\
\text { mencetak } \\
\text { destinasi } \\
\text { wisata }\end{array}$ & 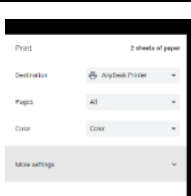 & Valid \\
\hline
\end{tabular}

\section{KESIMPULAN}

Berdasarkan analisa yang sudah dilakukan dan sudah pantas oleh apa yang ingin ditampakan, dapat diambil kesimpulan yaitu beserta adanya sistem aplikasi ini mampu menganugrahkan kemudahan yang efektif dan

efisien karena :

1. Masyarakat melakukan permintaan informasi objek pariwisata dengan datang direk ke Dinas Pemuda, Olahraga, Kebudayaan dan Pariwisata, setelah itu Staff Bidang Pariwisata menerima permintaan dan memberikan informasi objek wisata kepada masyarakat. 
2. Geographic Komputer merupakan sistem yang tepat untuk membantu menyajikan informasi objek pariwisata dan mencari lokasi-lokasi pariwisata. Sistem ini memiliki kemampuan untuk menyediakan informasi pariwisata, mengkategorikan destinasi pariwisata agar terstruktur lebih baik, memiliki fitur search agar mempermudah pencarian pariwisata, memiliki fitur save untuk destinasi yang akan kita kunjungi selanjutnya dan bisa mengakses melalui maps agar perjalanan bisa terarah. maps terdiri dari data dan deskripsi tentang data yang valid.

3. Tujuan pemetaan industri pariwisata sebagai tempat promosi ini adalah menyajikan sebuah informasi objek pariwisata di Kabupaten Tangerang dan kendala yang dihadapi tidak adanya suatu sistem informasi secara valid yang bisa di akses oleh user atau tourism secara realtime dan kendala yang dihadapi dalam pemetaan pariwisata ialah tiada memperoleh petunjuk direk tempat wisata kondisi ala geografisnya. Bab ini memerlukan teknologi yang dapat menyuguhkan informasi tujuan wisata yaitu Sistem informasi geografis (SIG) Sebagaimana perkara pada berita yang menyampaikan penjelasan ketika berita wisata layak meliputi laporan dan ilustrasi yang jelas dan akurat. Sehingga para pelancong yang ingin mengunjungi ke Kabupaten Tangerang namun tengah belum paham area atau daerah tujuan wisata yang menggoda untuk didatangi bisa mengerti.

4. Faktor-faktor yang dapat meningkatkan sektor pariwisata yaitu adanya sebuah Sistem informasi objek pariwisata sebagai media promosi, pesona tujuan Wisata, kemudahan, fasilitas pelayanan, dan prasarana.

\section{SARAN}

Bersumber pada dari pengkajian yang sudah pernah dijelaskan sebelumnya, penulis dapat mengiktisarkan saran sebagai berikut :

1. Wajib diadakan sosialisasi berkelanjutan secara lebih kreatif dengan cara melibatkan kang nong Kabupaten Tangerang, aktif sosial media seperti youtube, Instagram, Facebook atau membuat pesan broadcast melalui skenario penyebaran di grup whatsapp/telegram sehingga masyarakat yang aktif menggunakan smartphone akan dapat mengetahui bahwa ada Aplikasi Geographic Komputer untuk menyajikan informasi pariwisata yang valid dari Bidang Pariwisata.

2. Diharapkan sistem ini dapat memperluas cakupan pengunjung wisata tidak hanya di daerah Tangerang Raya saja tapi diluar daerah Tangerang Raya.

3. Ekspansi karakteristik asing sehingga keuntungan pola aplikasi dapat dimaksimalkan serta kian rapi.

4. Maintenance sistem secara rutin dan update informasi destinasi wisata secara berkala agar informasi yang diberikan valid

\section{DAFTAR PUSTAKA}

[1] Amrullah, Agit., Rifda Faticha Alfa A, Danang Sutedjo, Renna Yanwastika Ariyana, Hendi S dan Eri Sasmita Susanto.2016. Kajian Kebutuhan Perangkat Lunak Sistem Informasi Penilaian Prestasi Kerja Pegawai Pada Fakultas Adab dan Ilmu Budaya Universitas Islam Negeri Sunan Kalijaga Yogyakarta. Jurnal Seminar Nasional Teknologi Informasi dan MultimediaISSN: 2302-3805. Diambildari: http://ojs.amikom.ac.id/index.php/semnasteknomedia/article/download/1344/1 $\underline{263}$

[2] Anindita, M. 2015. Analisis Faktor-Faktor yang Mempengaruhi Tingkat Kunjungan ke Kolam Renang Boja. Semarang: Fakultas Ekonomika dan Bisnis Universitas Diponegoro. Aris, Andriani Dini, Romodor Apriyani dan Eka Sari Dian.2016. 
Perancangan aplikasi sistem informasi penjualan tiket pada PT Nur Rizky Pratama Travel Berbasis Web. Yogyakarta: Stmik Amikom Yogyakarta. Vol 4. number 1, Februari2016.Diambildari

https://ojs.amikom.ac.id/index.php/semnasteknomedia/article/view/1282. (1 Desember 2018).

[3] Cortez, D. M. A., Molina, C. M., Mata, K. E., \& Bermudez, J. R. D. 2015. Improving Customer Satisfaction through Smart Shopping: A Prototype. International Journal of Computer Science and Information Technologies, 6(2), 1141-1152. Crosstechno.com, 2019. Apa itu Flutter. Diakses tanggal 17 Agustus 2019 dari https://crosstechno.com/blog/view/apa-itu-flutter-.

[4] Dzulhaq, M. I., Tullah, R., \& Nugraha, P. S. (2017). Sistem Informasi Akademik Sekolah Berbasis Kurikulum 2013. Jurnal Sisfotek Global, 7(1).

[5] Hidayat, Wahyu. Riri Mahmuriyah. Dan Sri Ndayani Ratna Safitri. (2016). "Media Visual Berbentuk Katalog Produk Sebagai Media Promosi". Jurnal SENSI. Tangerang: STMIK Raharja (ISSN: 2461-1409. Vol.2 No. 2- Agustus 2016.

[6] Iswara, Danu. 2016. Pengaruh Kepercayaan, Kemudahan, Kualitas Informasi, Dan Persepsi Resiko Terhadap Keputusan Pembelian Studi Kasus Pada Pengguna Media Sosial Instagram di Kota.

[7] Maimunah, David Ericson Manalu, Dian Budi Kusuma 2017. Perancangan Prototype Visual Pada Bagian Desain Sebagai Media Informasi dan Promosi Pada PT. Sulindafin. Jurnal Teknik Informatika Vol.5 No.1 Yogyakarta : STMIK AMIKOM 